\title{
The Bulletin of the Psychonomic Society to be discontinued
}

After 1993, the Psychonomic Society will no longer be publishing the Bulletin of the Psychonomic Society. The Society's Publications Committee has decided that its original purpose-that of providing an outlet for quick, brief, unrefereed articles in experimental psychology at a time when publication lags were generally very long-has been fulfilled and is no longer needed.

Until the volume for 1993 is filled, the journal staff in Austin will continue to receive manuscripts submitted to the Bulletin. Based on past years' experience, this should occur in August or September; once the final issue of the year has been filled, no more papers will be accepted. Accordingly, submissions to the Bulletin should be made by August 1993.

For information about the publication policies of the Bulletin, please consult the inside front cover of a recent copy of the journal.

\section{Announcing a new Psychonomic Society journal Psychonomic Bulletin \& Review}

The Publications Committee of the Psychonomic Society has authorized a new journal: Psychonomic Bulletin \& Review. The new journal, a quarterly, with the first issue to appear in March 1994, will be a fully refereed journal, and its first editor will be Henry L. Roediger III of Rice University.

The journal will cover topics that form the basis of traditional experimental psychology, including

- animal learning and behavior

- judgment and decision-making

- memory and cognition

- psychobiology and cognitive neuropsychology

- psychophysics and perception

- social cognition and cognitive development

The aim is to publish broadly conceived papers of interest to experimental psychologists.

Papers in the following four categories will be considered: (1) review papers that summarize and synthesize a well-defined body of work; (2) theoretical papers that announce a new theory or provide a novel interpretation of a previously accepted theory; and (3) articles that may not state a new theory or review a body of literature but instead comment on trends in the field. These three types of articles-review, theory, and opinion-may be of any length. In general, such articles will not report new experimental data, although brief descriptions of new findings may be included to buttress a theoretical point.

In addition, Psychonomic Bulletin \& Review will also publish (4) brief reports which may include new experimental data. The same length restrictions for brief reports that were followed for publication in the Bulletin of the Psychonomic Society will be implemented, with papers not to exceed 4 journal pages. Longer manuscripts reporting experimental data should be submitted to one of the other appropriate journals published by the Psychonomic Society. Brief inquiries concerning the possible appropriateness of submissions may be made to the editor at the address below or by electronic mail (roedige@ricevm1.rice.edu).

Manuscripts may be submitted to: Henry L. Roediger III, Department of Psychology, Rice University, P.O. Box 1892, Houston, TX 77251-1892. 